\title{
Rare earthquake response spectra for typical site conditions in Hong Kong
}

\author{
R.K.L. Su ${ }^{a}$, C.L. Lee ${ }^{a}$, C.H. He ${ }^{a}$, H.H. Tsang ${ }^{b}$ \& C.W. Law $^{c}$ \\ a Department of Civil Engineering, The University of Hong Kong, Hong Kong, People's Republic of China \\ ${ }^{b}$ Department of Civil and Construction Engineering, Swinburne University of Technology, Melbourne, \\ Australia \\ ${ }^{c}$ Housing Department, The Government of the Hong Kong Special Administration Region, Hong Kong, \\ People's Republic of China
}

\begin{abstract}
Hong Kong is located in a region of low-to-moderate seismicity, the potential consequences in the event of a nearby major earthquake should not be underrated. In the past two decades, researchers have conducted many studies on this issue and it is now clear that design procedures should not be directly borrowed from other codes of practice without modifications. This paper aims at presenting the rare earthquake response spectra for typical rock and soil sites in Hong Kong, which form the basis of a seismic design procedure. The uniform hazard spectrum (UHS) for rock sites was obtained from seismic hazard assessment using probabilistic methods. Records from 16 boreholes, representing a wide range of local site conditions, were collected from different locations in Hong Kong. A site-specific response spectrum was then constructed based on the results from site response analyses. Moreover, the 16 site-specific response spectra have been grouped into four types based on the (initial) site natural periods, which allows convenient evaluation of the loading characteristics that are expected at different types of sites. Finally, the rare earthquake response spectra proposed for Hong Kong are compared with those constructed based on Chinese code (GB) and Eurocode (EC8).
\end{abstract}

Keywords: seismic design, response spectra, site natural period, rare earthquake, STRATA, Hong Kong. 


\section{Introduction}

Hong Kong is located in a region of low-to-moderate seismicity. If a major earthquake should occur in the vicinity of Hong Kong, the potential damage to building structures and the number of fatalities in the earthquake cannot be underrated. As reported by the Hong Kong Observatory (http://www.hko.gov.hk/), the strongest earth tremor was of intensity VI to VII (6-7) which occurred in 1918 and was caused by an earthquake near Shantou about $300 \mathrm{~km}$ from Hong Kong. The 1918 tremor caused minor damage to a few buildings, which was the only event with damage on record. The latest earth tremor of higher intensity was of intensity V to VI (5-6) that occurred in 1994, and was caused by an earthquake over the southern part of Taiwan Strait.

In recent years, a substantial amount of research has been carried out in the field of earthquake engineering and risk assessment. Ground motion characterisation of possible earthquake events, the associated probability of occurrence, as well as the response behaviours of the unique building stocks have been studied in Chandler et al. (2005; 2006b), Tsang (2006) and Su et al. (2008). The Buildings Department (BD) commissioned Arup as a consultant to study seismic effects on buildings in Hong Kong (Arup, 2003). The Geotechnical Engineering Office (GEO) recently appointed Arup to conduct a seismic hazard assessment study for Hong Kong and a pilot seismic microzonation assessment for the Northwest New Territories area (Arup 2012a; 2012b).

In Hong Kong, design for earthquake resistance of highways and railways was introduced in Structures Design Manual for Highways and Railways 2013 (SDM 2013). Basically, it follows the British Standards (BS EN 1998-1 (BSI, 2004); BS EN 1998-2) with some 
modifications for the Hong Kong situation. A reference return period (RP) of 475 years is adopted for no-collapse checks of Class I highway structures and the corresponding reference peak ground acceleration (PGA) is taken as $0.12 \mathrm{~g}$. A Type 2 elastic response spectrum as defined in Clause 3.2.2 of BS EN 1998-1 is adopted with ground type determined in accordance with Table 3.1 in Clause 3.1.2 of BS EN 1998-1. Site-specific hazard and ground motion response analyses for establishing the design response spectra are considered for special bridges and bridges of critical importance.

However, recent research has indicated that the seismic design procedure for Hong Kong should not be directly borrowed from other codes of practice without modifications because most of them were drafted for high seismicity regions. Design requirements and analysis methods that are appropriate for the local situation have to be developed. Tsang (2014) recommended that the RP for the no-collapse requirement for buildings in Hong Kong should be 2475 years (i.e. $2 \%$ probability of exceedance in 50 years of the life time of typical buildings in Hong Kong), and Su et al. (2014a) found that performance-based seismic design (PBSD) for buildings in Hong Kong is typically governed by the no-collapse requirement. In addition, site amplification is always significant for the weak ground motion levels in low-tomoderate seismicity regions, which causes the no-collapse requirement to dominate PBSD for all soil sites (Pappin et al., 2000).

This paper aims at proposing a set of rare earthquake response spectra (with a return period of 2475 years) for typical site conditions in Hong Kong, which form the basis of a seismic design procedure. The site-specific response spectrum is normally computed from the (simulated) ground motions at the bedrock level which is modified by the local site effects based on wave propagation theory. In this study, three groups of bedrock acceleration time 
histories of different earthquake scenarios were simulated by GENQKE (Lam et al., 2000; 2010; Tsang, 2006) and then adjusted to be UHS-compatible (refer to Section 3.1). Records from 16 boreholes were collected from different locations in Hong Kong. The perioddependent function of site-specific spectral ratios (SR) can be obtained from site response analysis using the computer program, STRATA (Kottke et al., 2013), and the site-specific response spectrum can then be constructed by scaling the bedrock UHS by the function of SR. The constructed site-specific response spectra have been further grouped into four types according to the site initial natural periods. Finally, the obtained rare earthquake response spectra for typical site conditions in Hong Kong will be compared with the corresponding response spectrum models in GB (MOHURD 2010) and EC8 (BSI 2004) for references.

\section{Methodology}

\subsection{Uniform Hazard Spectrum (UHS) for Reference Rock Sites in Hong Kong}

As the variation of the properties of crustal rocks in Hong Kong is relatively confined (Chandler et al., 2006a), sub-division of rock categories is not needed. Furthermore, the seismic hazard level varies by only $20-30 \%$ across Hong Kong (due to the different distances measured from the major potential earthquake sources) (Arup, 2012a). Such spatial variation does not justify the use of a seismic zoning map for general design purposes. Hence, a single design spectrum (DS) model was recommended for the reference rock sites, based on the average crustal rock properties in Hong Kong as characterised in Chandler et al. (2006a). The DS model for reference rock sites was recommended based on the UHS produced in Tsang and Chandler (2006), Tsang (2006), Tsang et al. (2009) and Arup (2012a), from which the results are consistent. The DS for rock sites with an RP of 2475 years was first formulated in Su et al. (2011), and slightly revised in Su et al. (2014a). 
The recommended idealised bedrock DS model for Hong Kong can be expressed in Equation (1) in the format of response spectral displacement (RSD) with 5\% damping versus natural period of structure (T), and corresponding to an RP of 2475 years.

$$
\begin{aligned}
& T \leq 0.23 \mathrm{~s} \quad: R_{T}(\mathrm{~mm})=0.56 \times(T / 2 \pi)^{2} \times 9810 \\
& 0.23<T \leq 1.0 \mathrm{~s}: R_{T}(\mathrm{~mm})=32 \times T \\
& 1.0<T \leq 5.0 \mathrm{~s}: \operatorname{RSD}_{T}(\mathrm{~mm})=32+14 \times(T-1)
\end{aligned}
$$

The compatible response spectral velocity (RSV) and acceleration (RSA) can be conveniently obtained by using Equations (2) and (3), respectively:

$$
\begin{aligned}
& R S V_{T}(\mathrm{~mm} / \mathrm{s})=R S D_{T}(\mathrm{~mm}) \times\left(\frac{2 \pi}{T}\right) \\
& R S A_{T}(g)=R S D_{T}(m m) \times\left(\frac{2 \pi}{T}\right)^{2} / 9810
\end{aligned}
$$

The bedrock UHS for Hong Kong in RSD and RSA formats with a confident period limit of $5.0 \mathrm{~s}$ is shown in Figure 1. This limit is determined based on the reliable period range in the stochastic simulation of ground motions based on the seismological model, which has been adopted in Tsang (2006) and Arup (2012a). Such period limit has also been adopted in the latest ground motion prediction model of Atkinson and Boore (2006).

\subsection{Design Earthquake Scenarios}

As there is no single earthquake scenario that can produce a response spectrum that matches the bedrock UHS as given in Section 2.1, a suite of most likely events is needed to match the bedrock UHS at different ranges of structural periods. For example, near-field earthquakes with smaller magnitudes usually contribute most to the short period demand, whilst far-field events with larger magnitudes may contribute more to the long period demand. Therefore, the earthquake scenarios (i.e. earthquake magnitude $(M)$ and the associated range of the distance 
$(R)$ from the site to the potential seismic sources) for the short period, intermediate period and long period ranges were recommended in Tsang and Chandler (2004) and Arup (2012a). The scenarios that are representative of the design earthquake action with an RP of 2475 years are summarised in Table 1. The earthquake scenarios can be used as a guideline for the selection or simulation of acceleration time histories that can be used in dynamic analysis.

For estimating the shaking levels at ground (soil) surface or performing dynamic structural analysis, acceleration time histories are required, which can be simulated using the computer program, GENQKE (Lam et al., 2000; 2010; Tsang, 2006), which was developed based on the seismological model. In order to capture the shear strain-dependent nonlinear response behaviour of soil sediments in site response analysis, it is recommended to modify, using a scaling factor, the acceleration time histories such that the corresponding modified response spectrum matches the bedrock UHS over a certain period range. Minimal scaling should be applied in order to retain the (spectral) characteristics of the original (unscaled) ground motions.

\subsection{Characterisation of Soil Sites}

Site effects are typically controlled by the total thickness of soil layers, especially in situations where a distinct soil-rock interface exists. The amplification ratio usually has a maximum value at the site natural period of the soil layer. A soil site is characterised by the weighted average initial shear wave velocity (SWV) $\left(V_{S, i}\right)$ and initial natural period $\left(T_{i}\right)$ of the soil layer down to the depth of much stiffer sediments or bedrock.

The value of $T_{i}$ can be estimated based on geophysical or geotechnical measurements with the use of Equation (4). It can be computed based on four times the shear-wave travel-time 
through materials from the surface to underlying stiff sediments or bedrock, if the thickness $\left(d_{i}\right)($ in $\mathrm{m})$ and initial SWV $\left(V_{i}\right)($ in $\mathrm{m} / \mathrm{s})$ of the individual soil layers are known.

$$
T_{i}=\sum_{i=1}^{n} \frac{d_{i}}{V_{i}} \times 4=\frac{4 H_{S}}{V_{S, i}}
$$

Alternatively, it can be expressed in terms of the total thickness of the soil layers $\left(H_{S}\right)$ (in m) and its weighted average initial SWV $\left(V_{S, i}\right)$ (in $\left.\mathrm{m} / \mathrm{s}\right)$.

The values of initial SWV of soil layers $\left(V_{i}\right)$ can be calculated from the SPT- $N$ values (Imai and Tonouchi, 1982), which are recorded in bore logs, using Equation (5):

$$
V_{i}=97 \times N^{0.314}
$$

It is shown in Su et al. (2014b) that the values obtained by Equation (5) are consistent with those obtained by the formula developed by Arup (2012b) in which in-situ measurements using geotechnical and geophysical methods were conducted locally across Hong Kong. Alternatively, as the site specific or in-situ data may be more appropriate for detailed design purposes, the empirical formulae (e.g. $V_{s}=122.37 \times N^{0.2409}$ ) proposed by Leung et al. (2010) and Arup (2012b) for predicting SWV for Hong Kong site conditions can also be adopted. Moreover, it was found by Arup (2012b) that sedimentary layers with SPT- $N$ values greater than 100 do not have significant effects on the value of the site natural period. However, as it is common to have sedimentary layers with SPT- $N$ values in the range of 100 to 250 being sandwiched in between softer soil layers, the SPT- $N$ value of 250 was recommended as the limit in order to avoid ambiguities in practice. Therefore, sedimentary layers with SPT- $N$ values greater than 250 can be omitted in the computations of site natural period and weighted average SWV.

\subsection{Site-Specific Response Spectrum}


For regions of low-to-moderate seismicity where recorded ground motions on soil sites are not available, site response can be simulated by using computer programs, such as SHAKE (Schnabel et al., 1972; Idriss and Sun, 1992), STRATA (Kottke et al., 2013) and SIREN (Oasys, 2006). The first two programs compute the nonlinear dynamic site response of a onedimensional soil column by an equivalent linear approximation using strain-dependent soil properties (e.g. shear modulus and damping ratio values) through an iterative process. SIREN operates in the time domain and analyses the response of a one-dimensional soil column subjected to earthquake at its base. The non-linear soil properties with hysteretic damping can be simulated by SIREN. Theoretically, the soil model used in SIREN can accurately simulate the actual hysteretic behaviour of soil layers. However, SHAKE has been popularly adopted globally since 1970's, whilst STRATA is a free and open-source software, which has adopted the same computational algorithm as SHAKE.

The site-specific response spectrum can be computed by multiplying the bedrock UHS (Equation (1)) by the period-dependent spectral ratio (SR) as:

$$
R S D_{S, T}(m m)=S R_{T} \times R S D_{T}(m m)
$$

in which $R S D_{S, T}$ is the soil surface $R S D$ at period $T$, and $S R_{T}$ is defined as the ratio between the $R S D$ of the soil surface and that of the bedrock at the same period $T$.

In this study, the soil layer model for each site was constructed using STRATA. The initial SWV $\left(V_{i}\right)$ of each soil sub-layer can be computed by Equation (5), and the SWV of the bedrock can be estimated by using the resonant period equivalence (RPE) method as proposed by Tsang et al. (2012). The nonlinear soil properties of shear modulus and damping reported in Hardin and Drnevich (1972a; 1972b) and Darendeli (2001) for each soil sub-layer were adopted. Recently, the nonlinear soil properties of local soils in Hong Kong have been 
proposed by Leung et al. (2010) that can also be adopted for simulating the dynamic soil properties. By using the UHS-compatible bedrock acceleration time histories as the input excitations, $S R$ can be directly obtained from the output data of STRATA and were further used to obtain the site-specific response spectrum using Equation (6). As the site-specific response spectrum is scaled from the bedrock UHS, the same period limit of $5.0 \mathrm{~s}$ shall be taken.

\section{Rare Earthquake Response Spectra for Hong Kong}

\subsection{Bedrock UHS-Compatible Acceleration Time Histories for Hong Kong}

The bedrock acceleration time histories (TH) that match the bedrock UHS (Figure 1) were simulated by using GENQKE (Lam et al., 2000; 2010; Tsang, 2006) for the selected earthquake scenarios for the near field (NF), medium field (MF) and far field (FF), as listed in Table 1. As GENQKE has been developed based on the seismological model, regional specific input parameters could be used, such that the key characteristics of the expected ground motions can be obtained. The regional wave modification factors (e.g. source factor, mid-crust factor, regional geometrical attenuation factor, regional whole path an elastic attenuation factor) and the local wave modification factors (upper crustal amplification and attenuation factor) for Hong Kong proposed by Chandler et al. (2005; 2006b) and Tsang (2006) were adopted in this study.

The bedrock acceleration time histories for NF, MF and FF synthesised by GENQKE are shown in Figure 2. Nine acceleration time histories for each earthquake scenario were generated. The values of the peak ground acceleration (PGA) range from 1.177 to $1.72 \mathrm{~m} / \mathrm{s}^{2}$ ( 0.12 to $0.175 \mathrm{~g}$ ) for $\mathrm{NF}, 0.785$ to $1.177 \mathrm{~m} / \mathrm{s}^{2}$ (0.08 to $0.12 \mathrm{~g}$ ) for MF and 0.4 to $0.59 \mathrm{~m} / \mathrm{s}^{2}$ (0.04 to 0.06 g) for FF. Moreover, the time steps for NF, MF and FF are 0.005 s, $0.01 \mathrm{~s}$ and 
$0.02 \mathrm{~s}$, respectively.

Figure 3 shows the corresponding average bedrock response spectra for each scenario in $R S V$ format. To match the bedrock UHS over a certain period range, scaling factors of 2.0, 2.2 and 1.6 were applied to modify (or amplify) the amplitudes of the bedrock acceleration time histories for the NF, MF and FF scenarios, respectively. Good agreements between the scaled enveloped $R S V$ and the idealised UHS were achieved with an acceptable error within $10 \%$ as shown in Figure 3. The scaled bedrock acceleration time histories will be used as the base excitations for site response analysis.

\subsection{Construction of Site-Specific Response Spectrum}

Borehole records from 16 different site locations in Hong Kong have been collected for constructing the site-specific response spectrum, based on the methodology introduced in Section 2 and using STRATA. Site S11 has been selected to demonstrate the procedure of constructing the site-specific response spectrum as follows.

The borehole records for site S11 have been summarised in Table 2. By assigning the thickness, the soil type, the initial SWV, the unit weight, as well as the shear modulus and damping properties, the numerical soil layer model of site S11 can be constructed in STRATA. After performing the site response analysis by using the scaled NF, MF and FF bedrock acceleration time histories as the input excitations, the average spectral ratios (SR) for each earthquake scenario can be obtained from the output data of STRATA.

Figure 4 shows the average SRs obtained from STRATA for NF, MF and FF, as well as the corresponding enveloped SR of the three earthquake scenarios. By multiplying the bedrock 
UHS (RSA or $R S D$ ) by the enveloped SR, as presented in Equation (6), the site-specific $R S A$ and $R S D$ can be constructed as shown in Figures 5(a) and 5(b), respectively.

Unlike the program-based site response methodologies, a simplified manual procedure has been developed by Tsang et al. (2006a) to provide an alternative convenient tool for rapid site response analysis for individual sites and can be expedited by the use of a spreadsheet calculation. The simplified site-specific DS model (Tsang et al., 2013) has a tripartite format with two corner periods, which is similar to those in various codes of practice. The first corner period is at the upper limit of the constant spectral acceleration region, whilst the second corner period is at the beginning (lower limit) of the constant spectral displacement region. It comprises a formula for estimating non-linear site amplification factor $(S)$ at the shifted site period ( $T_{S}$, Tsang et al., 2006a) and a set of formulae for estimating the reduction of shear modulus of soil and the amount of damping in soil (Tsang et al., 2006b). After simplifications for Hong Kong soil condition, the design charts for determining $S$ and $T_{S}$ in terms of initial SWV have been provided in Su et al. (2014b). Once $T_{S}$ is obtained, the maximum soil spectral response $R S D_{\max }$ (or $R S V_{\max }$ and $R S A_{\max }$ ) can be computed by multiplying the rock $R S D_{T s}$ (Equation (1)) with $S$. The corner periods can be converted accordingly by using the maximum soil spectral responses (e.g. $T_{1}=2 \pi \times R S V_{\max } / R S A_{\max }$ and $T_{2}=2 \pi \times R S D_{\max } /$ $\left.R S V_{\max }\right)$

Comparisons between the site-specific response spectrum obtained from STRATA and the simplified DS model can be seen in Figure 5. Generally speaking, the overall response spectrum obtained by the simplified DS model is more conservative than that obtained by STRATA. Hence, the soil DS model is recommended if more accurate site response analyses are not employed. 
The soil column profiles and the SPT- $N$ values versus depth of the soil layers for each site are shown in Figures 6 and Figure 7, respectively. The thickness and key material properties of the 16 borehole records are shown in Table 3. The site-specific response spectra for other sites can be constructed using the same procedure.

\subsection{Rare Earthquake Response Spectra for Typical Site Conditions}

Figure 8 shows the 16 site-specific response spectra in acceleration-displacement response spectrum (ADRS) format as obtained by using the same procedure as presented in Section 3.2. As site effects are controlled by the total thickness of soil layers, the amplification ratio usually has a maximum value at the site natural period of the soil layer. Hence, sites with short natural periods demonstrate high demand in the short-period range (governed by the high acceleration response), whilst sites with long natural periods show high demand in the long-period range (governed by the significant displacement response).

As further observed from Figure 8 and Table 3, the 16 site-specific response spectra can be grouped into four types (namely, Class Type 0, Class Type 1, Class Type 2 and Class Type 3), as shown in Table 3 and Figure 9, based on the site initial natural period. Despite the fact that the maximum site natural period obtained from the 16 sites is around 2.26s, the site natural periods that are larger than 2.26s (but smaller than 5.0s) are classified to be the Class Type 3 in this study. Moreover, the enveloped rare earthquake response spectrum in the tripartite format for each soil type is also shown in Figure 9. It is noted that a site with relatively thin and/or stiff soil layers and with the initial natural period $T_{i} \leq 0.15$ s (i.e. S01 to S03) can be classified as a rock site (i.e. Class Type 0), and the corresponding spectrum shall be the same as the bedrock UHS. 
The four (enveloped) rare earthquake response spectra for Hong Kong are shown in Figure 10 in ADRS and RSA formats. The maximum response spectral acceleration $\left(R S A_{\max }\right)$ and the corresponding two corner periods $\left(T_{1}\right.$ and $T_{2}$ ) of the tripartite response spectrum (see Equation 7) for each type have also been summarised in Table 4. This set of response spectra for the four typical site conditions could be a convenient engineering design tool. On one hand, once the borehole records of a specific site are collected, the site initial natural period can be easily computed by Equation (4) and its soil type can be quickly determined according to Table 3. On the other hand, if the lateral fundamental vibration periods of buildings are known (or predicted by period-height empirical formulae), then their seismic force and displacement demands under different types of soil conditions can be preliminarily evaluated.

$$
\begin{aligned}
& 0 \leq T \leq 0.1 s \quad: \quad R S A_{T}(g)=\frac{R S A_{\max }}{2.5}(1+15 \times T) \\
& 0.1 s \leq T \leq T_{1} \quad: \quad R S A_{T}(g)=R S A_{\max } \\
& T_{1} \leq T \leq T_{2} \quad: \quad R S A_{T}(g)=R S A_{\max }\left(\frac{T_{1}}{T}\right) \\
& T_{2} \leq T \leq 5.0 s \quad: \quad R S A_{T}(g)=R S A_{\max }\left(\frac{T_{1} T_{2}}{T^{2}}\right)
\end{aligned}
$$

\section{Comparison with Response Spectrum Models in Building Codes}

This study adopted the site initial natural period as the main parameter to classify the site conditions in Hong Kong, whilst most building codes adopt the average shear wave velocity down to a certain depth (e.g. $20 \mathrm{~m}$ or $30 \mathrm{~m}$ ) for site classification. It would be meaningful if the proposed four response spectra for Hong Kong could be compared with the response spectrum model adopted in existing building codes. GB and EC8 were selected in this comparison. 
In GB, the classification of a site is initially based on the equivalent $\mathrm{SWV}$ value $V_{s}$ of the soil sediments at the surface (with a depth not greater than $20 \mathrm{~m}$ ), while in EC8, it is based on the average SWV of the upper $30 \mathrm{~m}$ of the soil profile $\left(V_{s, 30}\right)$. The $V_{s}$ and $V_{s, 30}$ of the 16 sites in Hong Kong were computed and summarised in Table 3 for comparison. According to GB, most of the sites in Hong Kong can be classified as Site Class II (except that S01 is classified as Class $\mathrm{I}_{0}$ and S15 as Class III) while, according to EC8, Hong Kong Class Type 0 and Class Type 1 can be classified as Site Class B and Class Type 2 and Class Type 3 as Site Class C (except that site S15 is classified as Site Class D).

The proposed four rare earthquake response spectra for Hong Kong in RSA formats and those obtained from GB and EC8 are presented in Figure 11. It is noted that the basic seismic intensity of Hong Kong is recommended as 7 (upper category) in GB, and the corresponding $R S A_{\max }$ would be $0.72 \mathrm{~g}$ for rare earthquakes. To construct a design spectrum according to EC8, the value of $R S A_{\max }$ can be fixed at $0.56 \mathrm{~g}$ for rock site conditions. Generally speaking, the shapes of the spectra are similar and consistent; however, the spectral amplitudes vary substantially.

For Hong Kong Class Type 0 (rock site), the spectral amplitudes are lower than those of the corresponding spectra in GB ( $\mathrm{I}_{0}$ or II) and EC8 (B) for the whole period range. The results indicate higher seismic forces for buildings located on rock sites if the spectrum in either GB or EC8 was adopted.

For Hong Kong Class Type 1 and Class Type 2 (stiff and/or shallow soil site), the spectral demands are much higher than those of GB (II) and EC8 (B or C) at the short-period range up 
to around $1.0 \mathrm{~s}$. However, the spectral amplitudes are lower than those of GB and EC8 at the long-period range from $1.0 \mathrm{~s}$ to $5.0 \mathrm{~s}$, which concerns the design of medium-to-high-rise buildings that are prevailing in Hong Kong. In other words, the use of the spectrum in either GB or EC8 would produce over-conservative designs for most tall buildings in Hong Kong. It is noted that the importance of site natural period has not been reflected in empirically developed codified models, which were usually developed by averaging response spectral values from accelerograms recorded on a diversity of soil sites with different site natural period properties.

For Hong Kong Class Type 3 (soft and/or deep soil site), the corresponding spectra of GB of Hong Kong Class Type 3 interlaces with the GB spectrum for the whole period range, while it falls between Class C and Class D for the whole period range of EC8 spectra.

It is noted that in GB, there is a requirement of a minimum RSA of around $0.17 \mathrm{~g}$ to $0.13 \mathrm{~g}$ beyond the period of $2 \mathrm{~s}$ regardless of the soil type. Hence, the seismic demands on tall buildings designed by GB would be larger than those designed by the proposed Hong Kong response spectra, as the natural vibration periods of tall buildings typically fall within the long period range (e.g. > 2 s).

\section{Summary and Conclusions}

1. The hazard level for the reference (rock) site condition has firstly been established, which can be presented in the form of a uniform hazard spectrum (UHS) as obtained from probabilistic seismic hazard assessments. The rock UHS-compatible acceleration time 
histories can then be generated using the computer program, GENQKE, by adopting a suite of $M-R$ combinations that are representative of the seismicity pattern surrounding Hong Kong.

2. For a soil site, the site-specific spectral ratio function can be obtained from the computer program, STRATA. This can be used to scale the rock-UHS in order to obtain the sitespecific response spectrum. Alternatively, a simple procedure can be used to produce a tripartite site-specific design spectrum (DS) model without the use of a computer program which requires a lot of input parameters.

3. A set of rare earthquake response spectra for four types of site conditions are recommended for applications in Hong Kong, which represents the key outcomes of this study. They were developed following the substantial amount of research conducted in recent years. As the spectra were constructed based on the borehole records from 16 typical site locations in Hong Kong, more research works may be required to enrich the database of the soil profiles for further refinement of the results, which can also incorporate the findings of other local research on soil dynamic properties (e.g. Leung et al. (2010) and Arup (2102b)). Moreover, liquefaction assessment is considered as a separate issue, and is not taken into account in this paper.

4. Comparisons of the proposed four rare earthquake response spectra for Hong Kong and the response spectrum models in GB and EC8 were conducted and significant differences can be observed. The spectral amplitudes for Hong Kong Class Type 0 (rock site) are lower than those of the corresponding spectra in GB and EC8 for the whole period range. For Hong Kong Class Type 1 and Class Type 2, higher demand at the short period range 
and lower demand at the long period range can be observed. For Hong Kong Class Type 3, the proposed spectrum is reasonably close to the corresponding spectrum models in GB and EC8.

\section{Acknowledgment}

The research described here was supported by the Small Project Fund (2014-15) of The University of Hong Kong. The authors would also like to thank Mr. Daniel T.W. Looi, Department of Civil Engineering, The University of Hong Kong, for his valuable discussions.

\section{REFERENCES}

Arup (2003). Evaluation of Seismic Response of Buildings, Consultancy Agreement No. CAO K49, the Seismic Effects on Buildings in Hong Kong, Buildings Department, The Government of the HKSAR.

Arup (2012a). Final Report on Overall Seismic Hazard Assessment. Pilot Seismic Microzonation Study in North-west New Territories for the Study of Potential Effect of Earthquake on Natural Terrain Investigation, Agreement No. CE49/2008(GE), Landslip Prevention and Mitigation Programme, Geotechnical Engineering Office, Civil Engineering and Development Department, The Government of the HKSAR.

Arup (2012b). Report on the Seismic Microzonation Assessment. Pilot Seismic Microzonation Study in North-west New Territories for the Study of Potential Effect of Earthquake on Natural Terrain Investigation, Agreement No. CE49/2008(GE), Landslip Prevention and Mitigation Programme, Geotechnical Engineering Office, Civil Engineering and Development Department, The Government of the HKSAR. 
Atkinson GM and Boore DM (2006). Earthquake ground-motion prediction equations for eastern North America. Bulletin of the Seismological Society of America, 96(6):2181-2205.

BS EN 1998-2: 2005. Eurocode 8: Design of structures for earthquake resistance-Part 2: Bridges, Design for earthquake resistance, British Standards Institute, UK.

BSI (2004). Eurocode 8: Design of Structures for Earthquake Resistance, Part 1: General Rules, Seismic Actions and Rules for Buildings, British Standards Institute, UK.

Chandler AM, Lam NTK and Tsang HH (2005). Shear wave velocity modelling in crustal rock for seismic hazard analysis. Soil Dynamics and Earthquake Engineering, 25(2): 167185.

Chandler AM, Lam NTK and Tsang HH (2006a). Regional and local factors in attenuation modelling: Hong Kong case study. Journal of Asian Earth Sciences, 27(6): 892-906.

Chandler AM, Lam NTK and Tsang HH (2006b). Near-surface attenuation modelling based on rock shear-wave velocity profile. Soil Dynamics and Earthquake Engineering, 26(11): 1004-1014.

Darendeli MB (2001). Development of a New Family of Normalized Modulus Reduction and Material Damping Curves. PhD Dissertation, University of Texas at Austin, Austin, Texas.

MOHURD (2010). GB 50011-2010, Code for Seismic Design of Buildings, The Ministry of Housing and Urban-Rural Development of the People's Republic of China (MOHURD), China Architecture \& Building Press, Beijing, China.

Hardin BO and Drnevich VP (1972a). Shear modulus and damping in soils: measurement and parameter effects. Journal of the Soil Mechanics and Foundations Division, ASCE, 98(6): 603-624.

Hardin BO and Drnevich VP (1972b). Shear modulus and damping in soils: design equations and curves. Journal of the Soil Mechanics and Foundation Division, ASCE, 98(7): 667-692. 
SDM (2013). Structures Design Manual for Highways and Railways (2013 Edition). Highways Department, The Government of the HKSAR.

Idriss IM and Sun JI (1992). SHAKE91: A computer program for conducting equivalent linear seismic response analyses of horizontally layered soil deposits. Department of Civil and Environmental Engineering, University of California Davis.

Imai $\mathrm{T}$ and Tonouchi K (1982). Correlation of $\mathrm{N}$-value with S-wave velocity and shear modulus. In: Proceedings of the $2^{\text {nd }}$ European Symposium on Penetration Testing, pp. 57-72.

Kottke AR, Wang XY and Rathje EM (2013). Technical Manual for Strata, Geotechnical Engineering Center, Department of Civil, Architectural, and Environmental Engineering, University of Texas, USA.

Lam NTK, Wilson JL and Hutchinson GL (2000). Generation of synthetic earthquake accelerograms using seismological modelling: a review. Journal of Earthquake Engineering, 4(3): 321-354.

Lam N, Wilson J and Tsang HH (2010). Modelling earthquake ground motions by stochastic method. In: Stochastic Control, Chris Myers (Ed.), ISBN: 978-953-307-121-3, InTech, pp. 475-492.

Leung E, Pappin J and Koo R (2010). Determination of small strain modulus and degradation for in-situ weathered rock and Old Alluvium deposits. Fifth International Conference on Recent Advances in Geotechnical Earthquake Engineering and Soil Dynamics and Symposium in Honor of Professor I.M. Idriss, San Diego, California, USA. May 24-29, 2010.

Oasys, 2006. SIREN, Oasys Ltd., London. 
Pappin JW, Lubkowski ZA and King RA (2000). The significance of site response effects on performance based design. In: Proceedings of the 12th World Conference on Earthquake Engineering, Auckland, New Zealand. January 30-February 4, 2000.

Schnabel PB, Lysmer J and Seed HB (1972). A computer program for earthquake response analysis of horizontally layered sites. Earthquake Engineering Research Center Report: EERC 72-12, University of California at Berkeley, USA.

Su RKL, Lam NTK and Tsang HH (2008). Seismic drift demand and capacity of nonseismically designed buildings in Hong Kong. Electronic Journal of Structural Engineering, $8,110-120$.

Su RKL, Tsang HH and Lam NTK (2011). Seismic Design of Buildings for Hong Kong Conditions. The University of Hong Kong, Hong Kong. 192 pp.

Su RKL, Looi DTW, Tang TO and Law CW (2014a). Performance based seismic design for tall buildings in Hong Kong, The Proceedings of Advances in Earthquake Engineering. Joint Structural Division Annual Seminar 2014, 19 May 2014, Hong Kong, 07-131.

Su RKL, Lee CL, Tsang HH and Tang TO (2014b). Final report on provision of consultancy services of development of design reference for enhanced ductility design of housing authority buildings, Agreement No. CB20130721, Hong Kong Housing Authority, The Government of the HKSAR.

Tsang HH and Chandler AM (2004). Site-specific seismic hazard analysis in metropolitan cities: a Hong Kong case study. In: Proceedings of the Third International Conference on Continental Earthquakes-Mechanism, Prediction, Emergency Management and Insurance, Beijing, China, July 12-14, 2004.

Tsang HH (2006). Probabilistic Seismic Hazard Assessment: Direct Amplitude-Based Approach. PhD Thesis, Department of Civil Engineering, The University of Hong Kong. 
Tsang HH and Chandler AM (2006). Site-Specific Probabilistic Seismic-Hazard Assessment: Direct Amplitude-Based Approach. Bulletin of the Seismological Society of America, 96(2), 392-403.

Tsang HH, Chandler AM and Lam NTK (2006a). Estimating nonlinear site response by single period approximation. Earthquake Engineering and Structural Dynamics, 35(9): 1053-1076.

Tsang HH, Chandler AM and Lam NTK (2006b). Simple models for estimating period-shift and damping in soil. Earthquake Engineering and Structural Dynamics, 35(15): 1925-1947.

Tsang HH, Su RKL, Lam NTK and Lo SH (2009). Rapid assessment of seismic demand in existing building structures. The Structural Design of Tall and Special Buildings, 18(4): 427-439.

Tsang HH, Sheikh MN and Lam NTK (2012). Modelling shear rigidity of stratified bedrock in site response analysis. Soil Dynamics and Earthquake Engineering, 34(1): 89-98.

Tsang HH, Lam NTK and Wilson JL (2013). A displacement based soil amplification model for low and moderate seismicity regions. In: Proceedings of the IStructE Conference on Structural Engineering in Hazard Mitigation, Beijing, China, October 28-29, 2013.

Tsang HH (2014). Seismic performance requirements and collapse risk of structures. In: Proceedings of the Annual Seminar: Advances in Seismic Engineering, Joint Structural Division of The Hong Kong Institution of Engineers (HKIE) and The Institution of Structural Engineers (IStructE), Hong Kong, May 19, 2014. 
Table 1 Rare earthquake scenarios (with return period of 2475 years) for Hong Kong

\begin{tabular}{|c|c|c|c|c|c|}
\hline $\begin{array}{c}\text { Distance } \\
\text { range }\end{array}$ & $\begin{array}{c}\text { Period range } \\
(\mathrm{sec})\end{array}$ & $M$ range & $\begin{array}{c}R \text { range } \\
(\mathrm{km})\end{array}$ & Selected $M$ & $\begin{array}{c}\text { Selected } R \\
(\mathrm{~km})\end{array}$ \\
\hline $\begin{array}{c}\text { Near field } \\
(\mathrm{NF})\end{array}$ & $\begin{array}{c}\text { Short period } \\
T<0.5\end{array}$ & 5.5 to 6.0 & 20 to 40 & 6.0 & 30 \\
\hline $\begin{array}{c}\text { Medium field } \\
(\mathrm{MF})\end{array}$ & $\begin{array}{c}\text { Intermediate } \\
\text { period } \\
0.4<T<2.0\end{array}$ & 6.7 to 7.2 & 60 to 120 & 7.2 & 120 \\
\hline Far field (FF) & $\begin{array}{c}\text { Long period } \\
1.0<T\end{array}$ & 7.5 to 8.0 & 250 to 350 & 8.0 & 250 \\
\hline
\end{tabular}

Table 2 Borehole records for S11 site

\begin{tabular}{|c|c|c|c|c|}
\hline Soil Type & Thickness $d_{i}(\mathrm{~m})$ & $S P T-N$ & $V_{i}(\mathrm{~m} / \mathrm{s})=97 \times N^{0.314}$ & $4 d_{i} / V_{i}$ \\
\hline Fill (Gravel, Cobble) & 2.0 & 10 & 200 & 0.040 \\
\hline Fill (Cobble, Sand) & 6.5 & 11 & 206 & 0.126 \\
\hline Fill (Gravel, Sand) & 4.0 & 27 & 273 & 0.059 \\
\hline Fill (Sand) & 2.7 & 23 & 260 & 0.042 \\
\hline Fill (Cobble, Silt) & 2.8 & 13 & 217 & 0.052 \\
\hline Marine Deposit (Clay) & 2.5 & 16 & 232 & 0.043 \\
\hline Marine Deposit (Clay) & 2.5 & 20 & 248 & 0.040 \\
\hline Marine Deposit (Clay) & 2.5 & 19 & 245 & 0.041 \\
\hline Marine Deposit (Clay) & 2.5 & 25 & 267 & 0.038 \\
\hline Marine Deposit (Sand) & 2.5 & 33 & 291 & 0.034 \\
\hline Marine Deposit (Sand) & 2.7 & 35 & 296 & 0.036 \\
\hline Alluvium (Gravel) & 2.5 & 38 & 304 & 0.033 \\
\hline & $H_{S} \mathbf{3} \mathbf{3 5 . 7} \mathbf{~ m}$ & & $V_{S, i}=\mathbf{2 4 4 . 7} \mathbf{~} / \mathbf{s}$ & $\mathbf{T}_{\boldsymbol{i}}=\mathbf{0 . 5 8 4} \mathbf{~ s}$ \\
\hline
\end{tabular}


Table 3 Summary of the site classification results and feature characteristics of the 16 typical sites in Hong Kong

\begin{tabular}{|c|c|c|c|c|c|c|c|c|}
\hline Site types & $\begin{array}{c}\text { Site } \\
\text { name }\end{array}$ & $T_{i}(\mathrm{~s})$ & $H_{S}(\mathrm{~m})$ & $\begin{array}{c}V_{S, i} \\
(\mathrm{~m} / \mathrm{s})\end{array}$ & $\begin{array}{c}V_{s} \\
(\mathrm{~m} / \mathrm{s})\end{array}$ & $\begin{array}{l}V_{s, 30} \\
(\mathrm{~m} / \mathrm{s})\end{array}$ & $\mathbf{G B}^{*}$ & $\mathbf{E C} 8^{* *}$ \\
\hline \multirow{3}{*}{$\begin{array}{c}\text { Class Type } 0 \\
\text { (Rock) } \\
\left(T_{i}<0.15 \mathrm{~s}\right)\end{array}$} & S01 & 0.010 & 0.5 & 200 & $>800$ & $800 \sim 1000$ & $I_{0}$ & B \\
\hline & S02 & 0.094 & 5.4 & 232 & 232 & 626 & II & B \\
\hline & S03 & 0.121 & 9.6 & 318 & 279 & 621 & II & B \\
\hline \multirow{4}{*}{$\begin{array}{c}\text { Class Type } 1 \\
\left(0.15<T_{i}<0.3 \mathrm{~s}\right)\end{array}$} & S04 & 0.186 & 14.5 & 312 & 290 & 518 & II & B \\
\hline & S05 & 0.223 & 18.8 & 337 & 321 & 484 & II & B \\
\hline & S06 & 0.282 & 20.0 & 284 & 251 & 388 & II & B \\
\hline & S07 & 0.284 & 17.2 & 242 & 242 & 378 & II & B \\
\hline \multirow{5}{*}{$\begin{array}{l}\text { Class Type } 2 \\
\left(0.3<T_{i}<0.7 \mathrm{~s}\right)\end{array}$} & S08 & 0.370 & 19.1 & 206 & 206 & 304 & II & $\mathrm{C}$ \\
\hline & S09 & 0.449 & 27.0 & 241 & 215 & 251 & II & $\mathrm{C}$ \\
\hline & S10 & 0.547 & 30.4 & 222 & 212 & 222 & II & $\mathrm{C}$ \\
\hline & S11 & 0.584 & 35.7 & 245 & 227 & 237 & II & $\mathbf{C}$ \\
\hline & $\mathrm{S} 12$ & 0.678 & 41.0 & 242 & 195 & 222 & II & $\mathrm{C}$ \\
\hline \multirow{4}{*}{$\begin{array}{l}\text { Class Type } 3 \\
\left(0.7<T_{i}<5 \mathrm{~s}\right)\end{array}$} & S13 & 0.815 & 53.6 & 263 & 207 & 214 & II & $\mathbf{C}$ \\
\hline & S14 & 0.863 & 69.0 & 319 & 277 & 269 & II & C \\
\hline & S15 & 1.119 & 75.1 & 268 & 137 & 165 & III & $\mathbf{D}$ \\
\hline & S16 & 2.261 & 146.8 & 260 & 227 & 212 & II & $\mathrm{C}$ \\
\hline
\end{tabular}

\section{GB}

$V_{s}>800 ; \quad H_{S}=0\left(I_{0}\right)$

$800 \geqq V_{s}>500 ; \quad H_{S}=0\left(I_{1}\right)$

$500 \geqq V_{s}>250 ; \quad H_{S}<5\left(\right.$ I $\left._{1}\right) ; \quad H_{S} \geqq 5$ (II)

$200 \geqq V_{S}>150 ; \quad H_{S}<3\left(\right.$ I $\left._{1}\right) ; \quad H_{S}=3-50$ ( II ); $\quad H_{S}>50$ (III)

$V_{s} \leqq 150 ; \quad H_{S}<3\left(\right.$ I $\left._{1}\right) ; \quad H_{S}=3-15($ II $) ; \quad H_{S}=15-80($ III $) ; \quad H_{S}>80(\mathbf{I V})$

\section{${ }^{* *}$ EC8}

$V_{s, 30}>800 ; \quad \mathbf{A}$

$360-800 ; \quad$ B

$180-360 ; \quad \mathbf{C}$

$V_{s, 30}<180 ; \quad \mathbf{D}$

Table 4 Values of $R S A_{\max }$ and corner periods $\left(T_{1}\right.$ and $\left.T_{2}\right)$ for the proposed rare earthquake 


\begin{tabular}{|c|c|c|c|}
\hline Site types & $R S A_{\max }(\mathrm{g})$ & $T_{1}(\mathrm{~s})$ & $T_{2}(\mathrm{~s})$ \\
\hline Class Type 0 & 0.56 & 0.23 & $1.00^{*}$ \\
\hline Class Type 1 & 1.50 & 0.30 & 0.55 \\
\hline Class Type 2 & 1.20 & 0.45 & 0.80 \\
\hline Class Type 3 & 0.65 & 0.75 & 2.00 \\
\hline
\end{tabular}

${ }^{*}$ The RSA for Class Type 0 can be calculated by using Equation (1) in Section 2.1. The spectral shape for Class Type 0 beyond $T_{2}$ is different from that of the other three spectra.
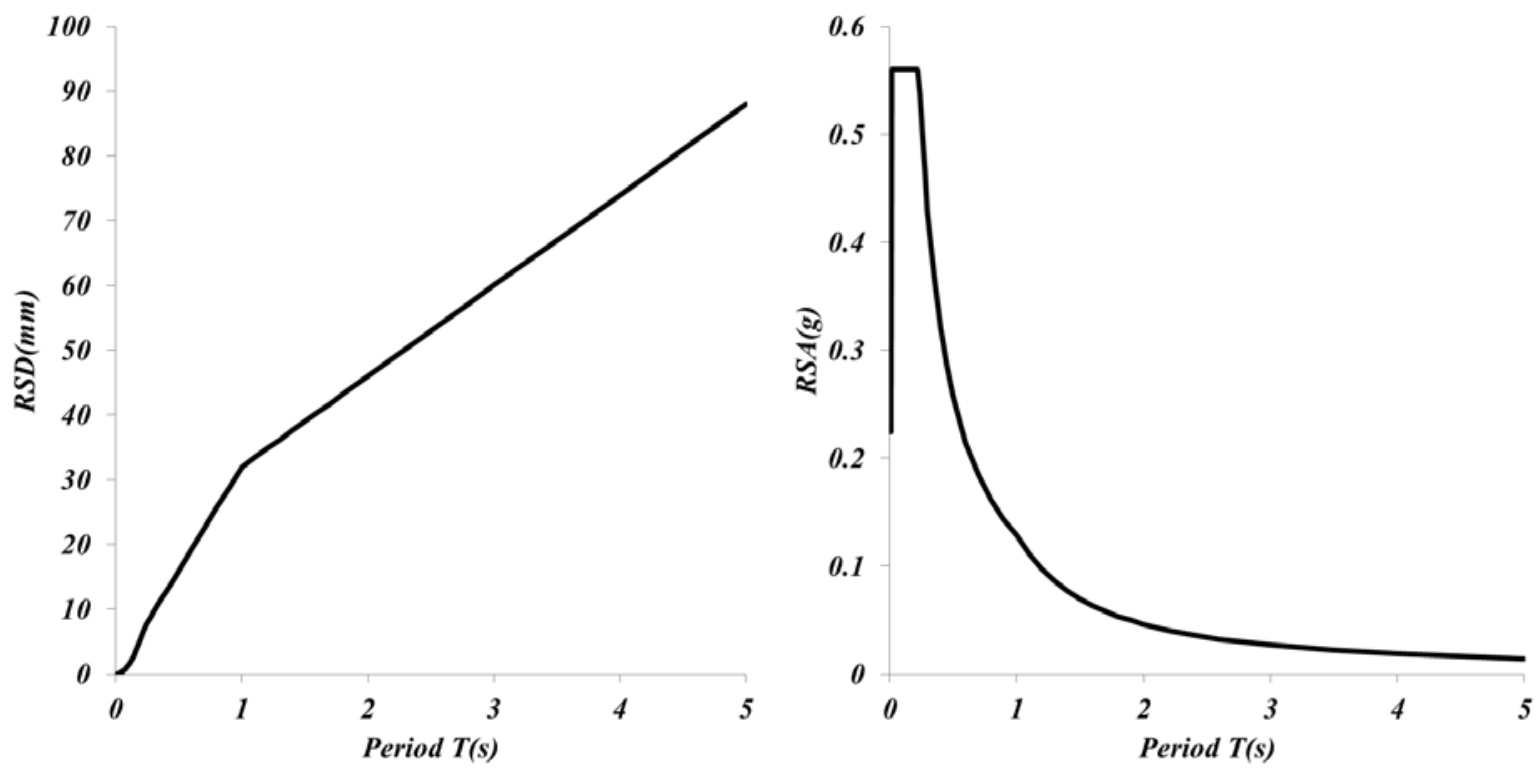

Figure 1 Rock UHS for Hong Kong presented in RSD (left) and RSA (right) formats 

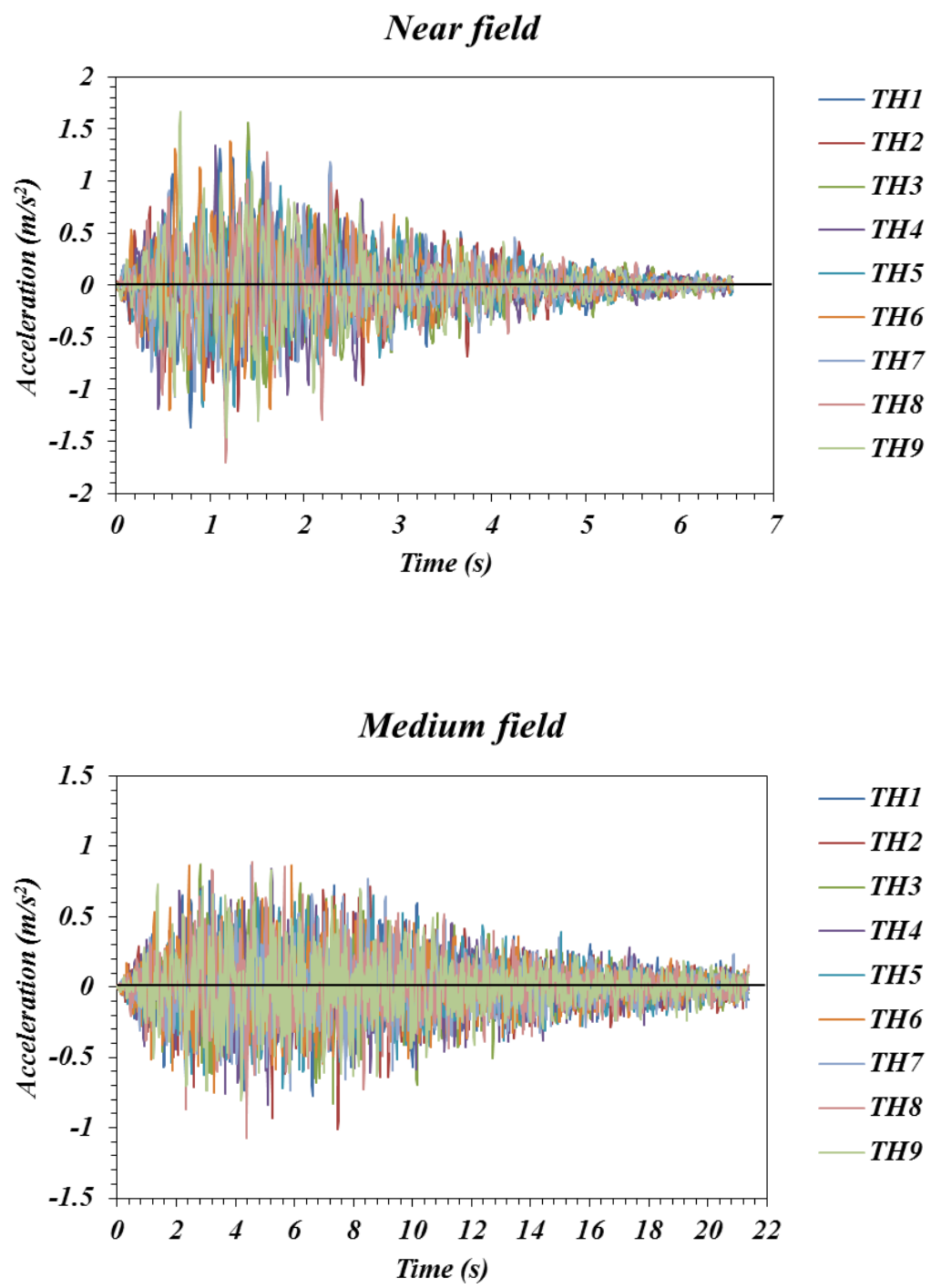

Far field

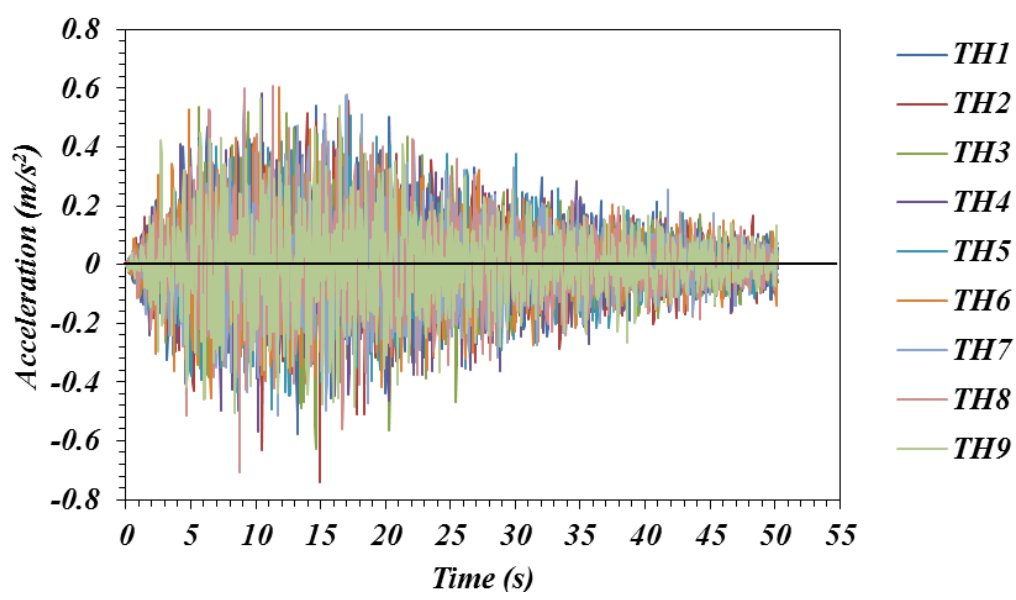

Figure 2 Acceleration time histories (TH) of near field (NF), medium field (MF) and far field (FF) earthquake scenarios generated by program, GENQKE, for rock sites in Hong Kong 


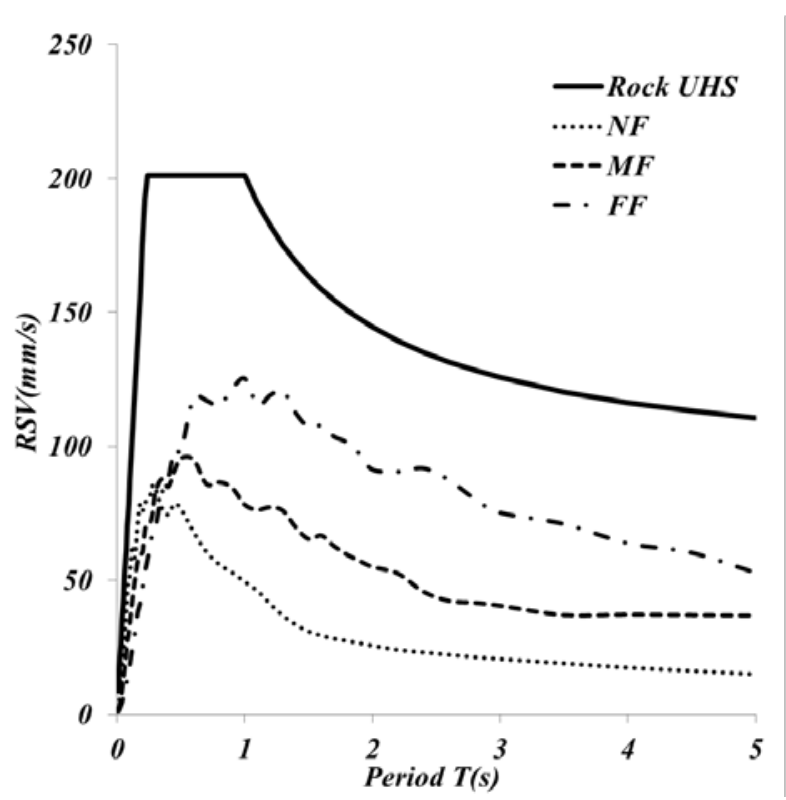

Figure 3(a)

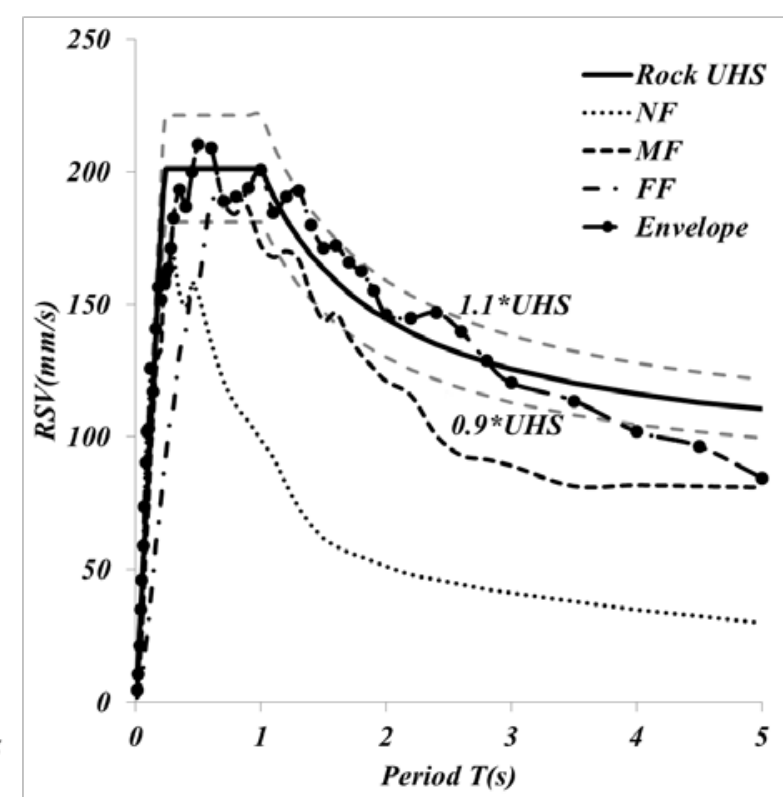

Figure 3(b)

Figure 3 Comparisons of the scenario-based response spectra and the rock UHS in RSV format: (a) original (unscaled) spectra; (b) scaled spectra

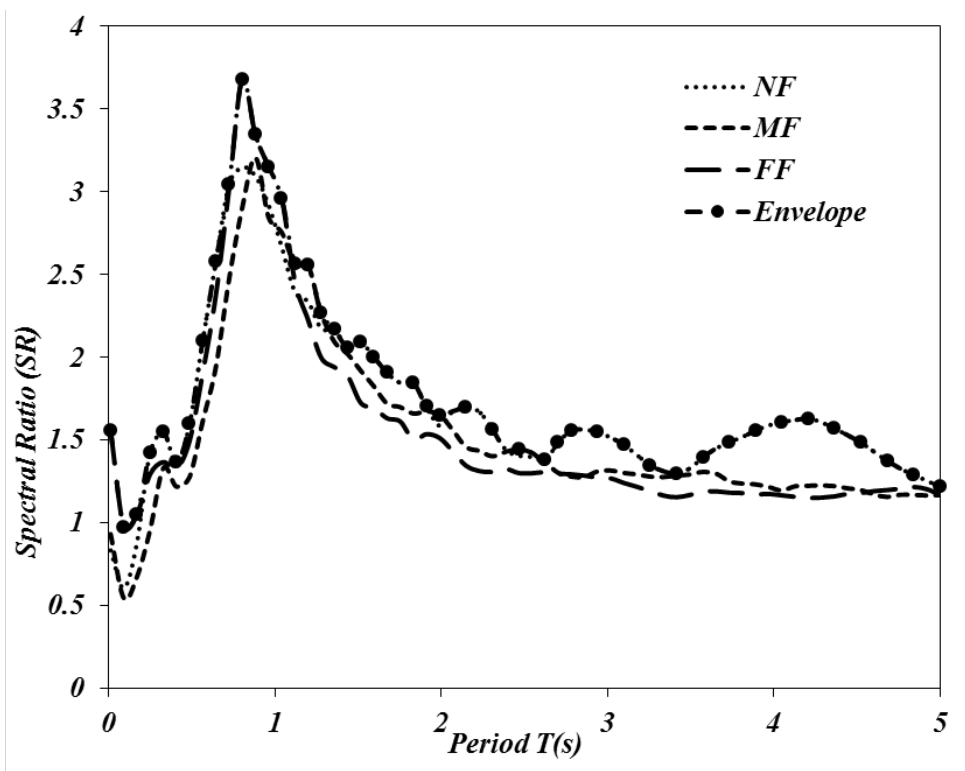

Figure 4 Individual and enveloped site-specific spectral ratios (SR) for site S11 


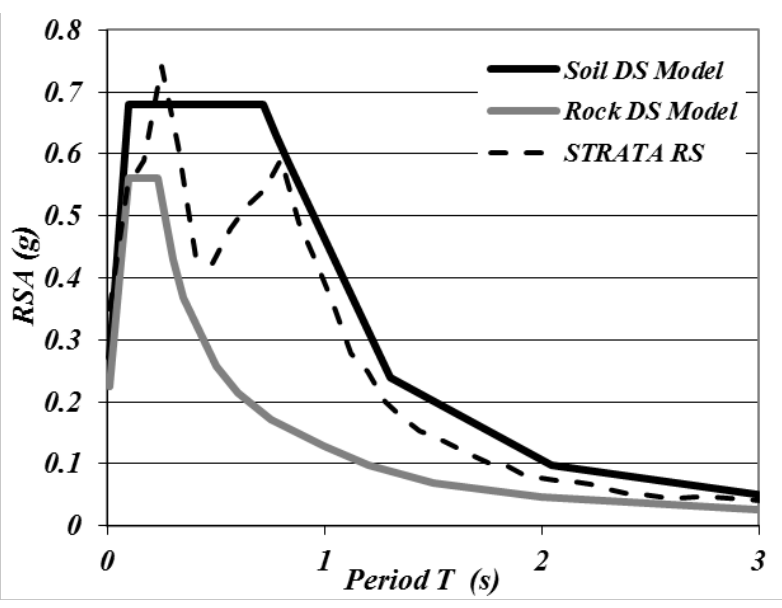

Figure 5(a)

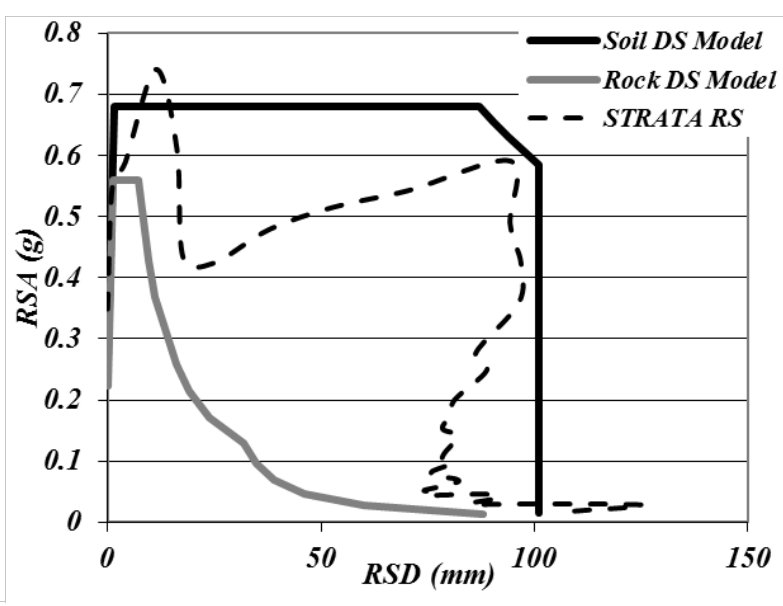

Figure 5(b)

Figure 5 Comparisons of site-specific response spectra obtained from STRATA and the simplified method for site S11: (a) in RSA format; (b) in ADRS format

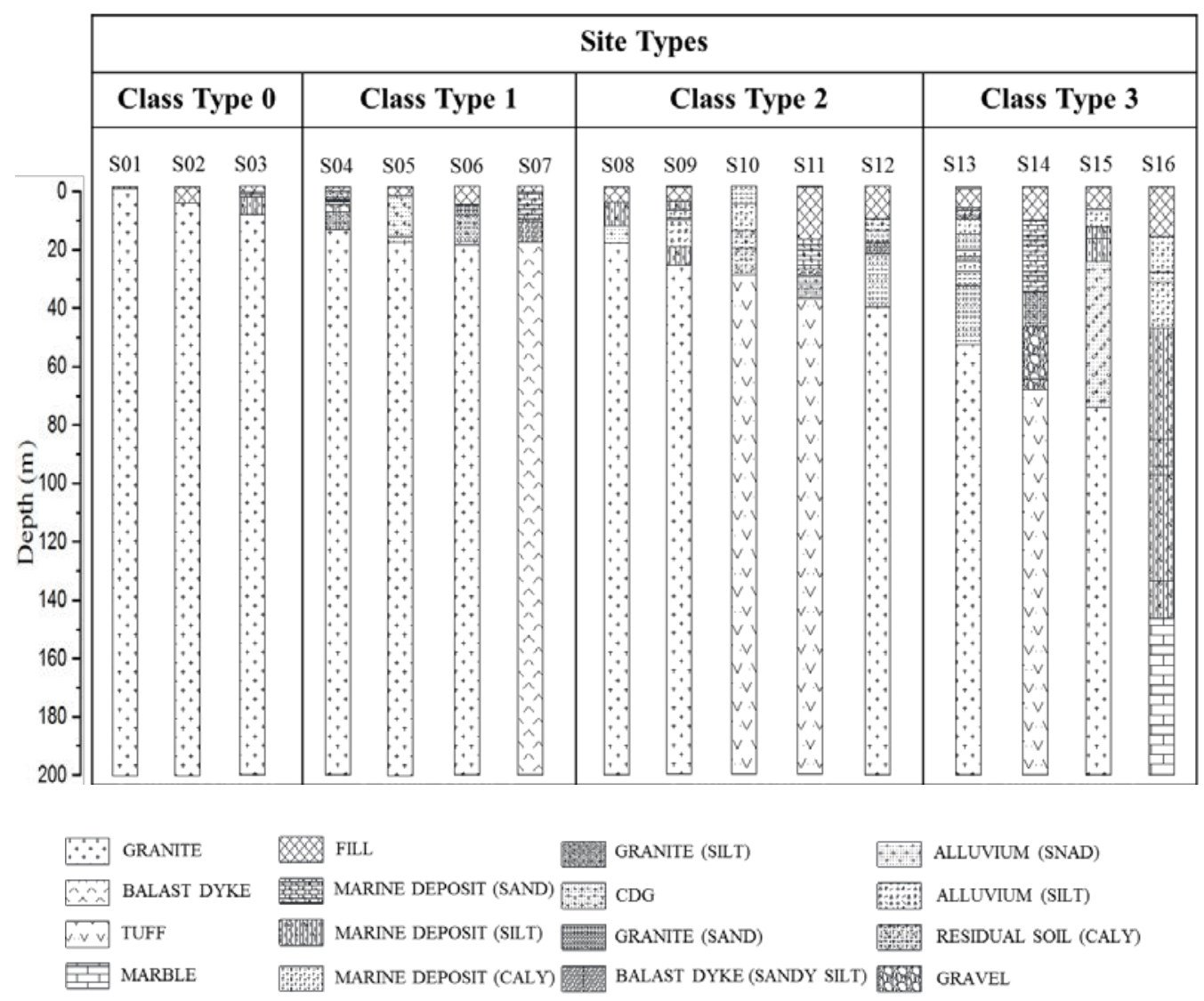

Figure 6 Borehole records of the 16 selected sites in Hong Kong 

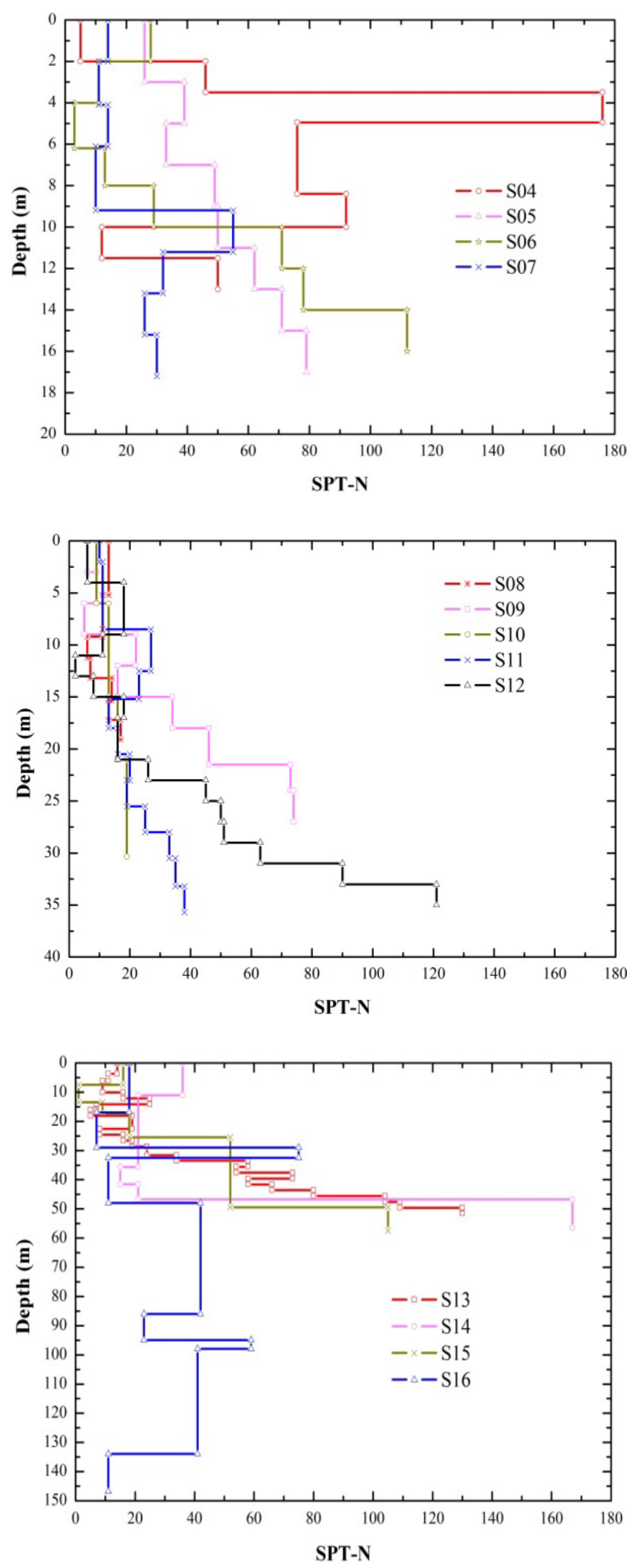

Figure 7 SPT- $N$ profiles of the 13 soil sites in Hong Kong 


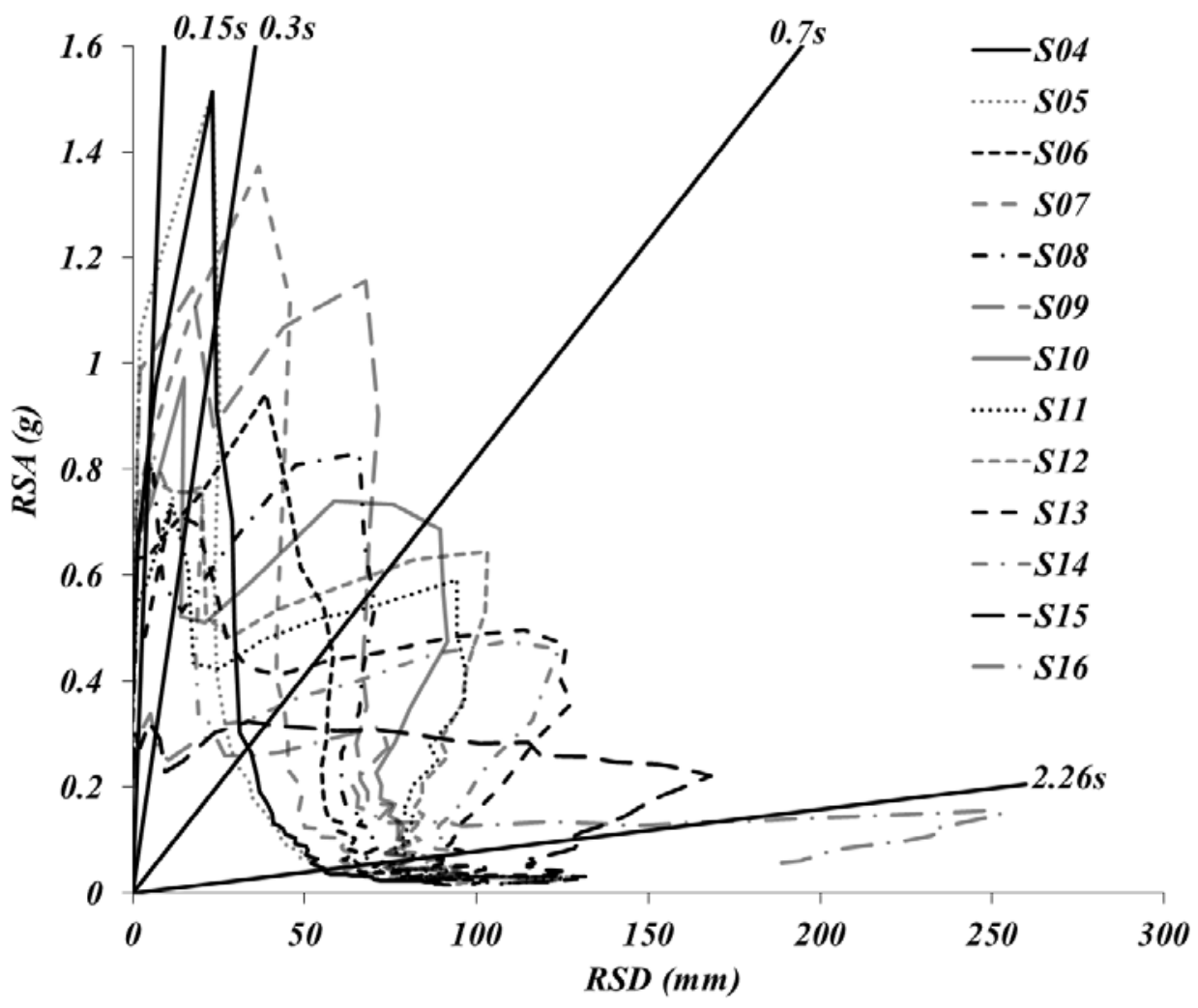

Figure 8 Site-specific response spectra of the 13 soil sites in Hong Kong 

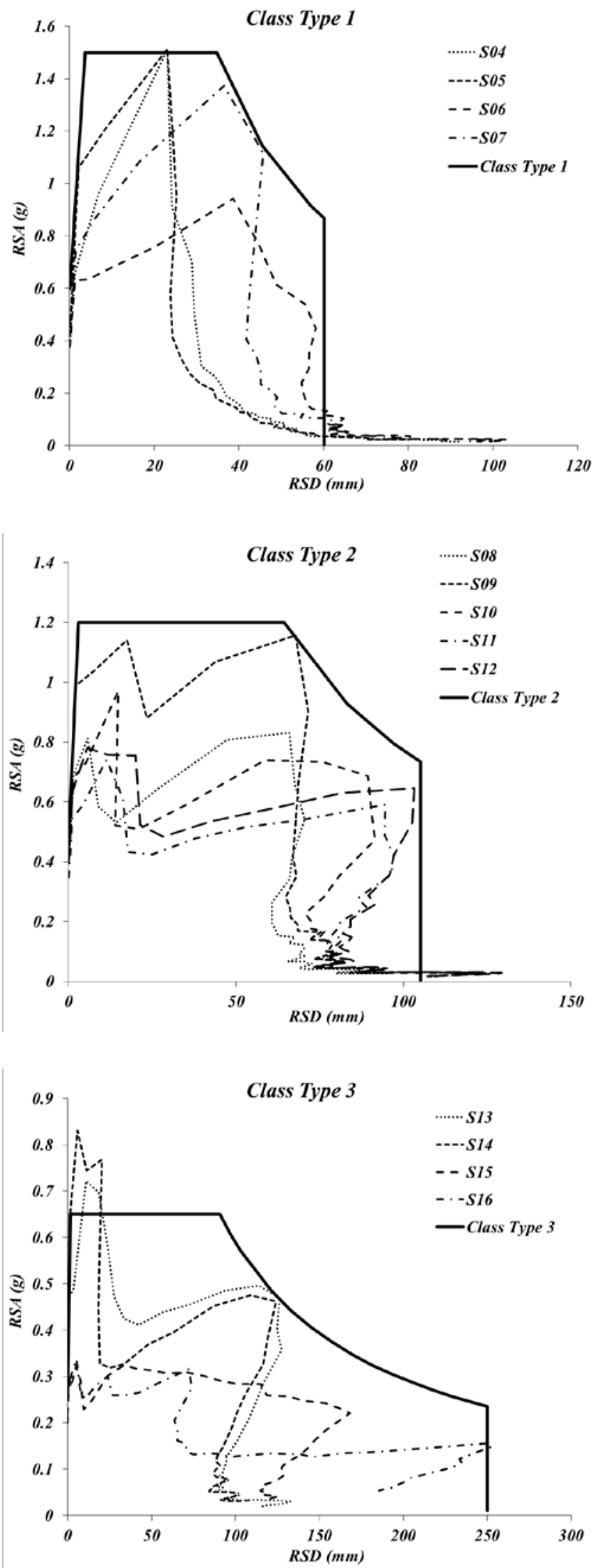

Figure 9 Site-specific response spectra and proposed three rare earthquake response spectra for soil sites in Hong Kong 

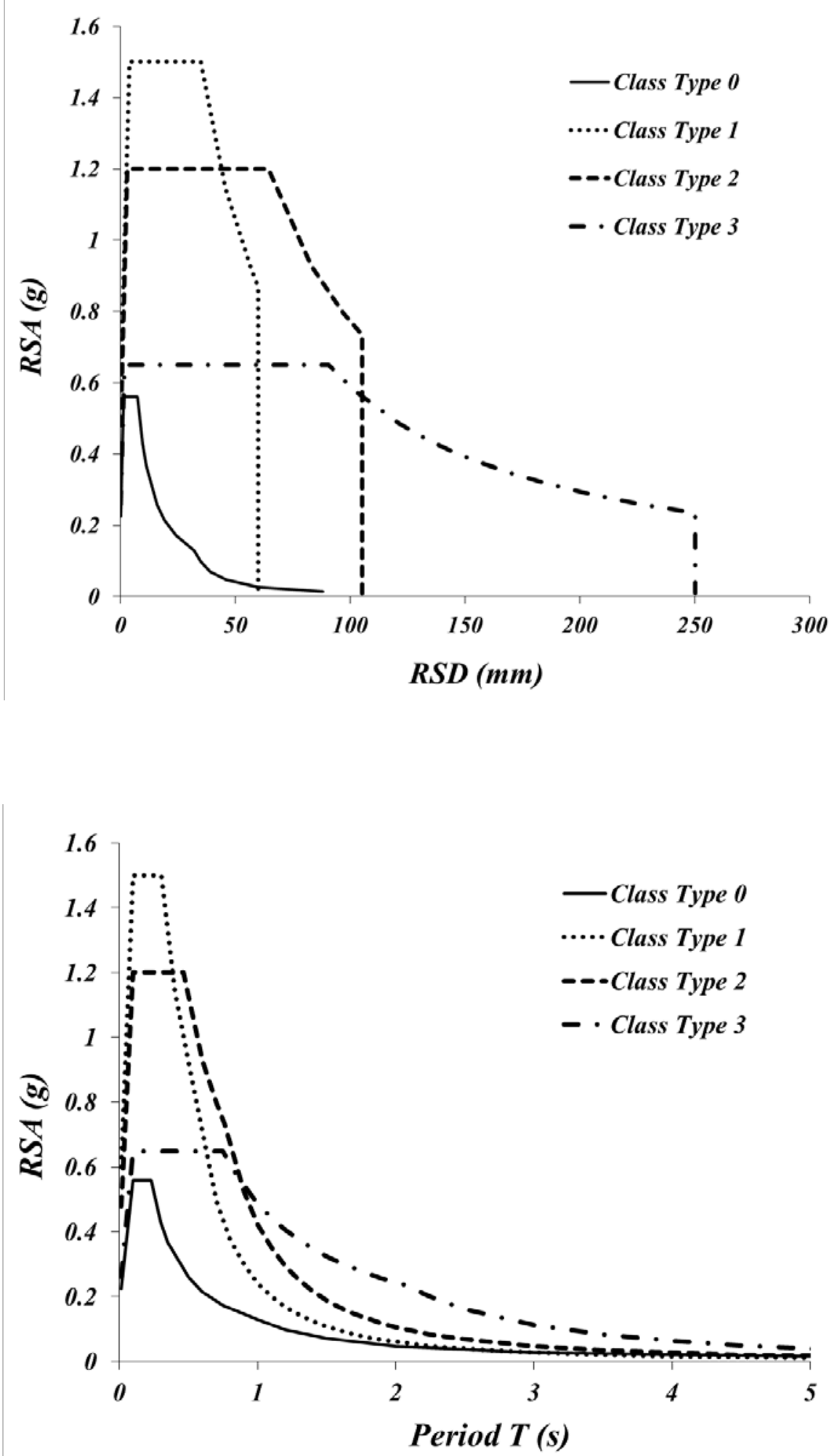

Figure 10 Proposed four rare earthquake response spectra for Hong Kong in ADRS (top) and RSA (bottom) formats 

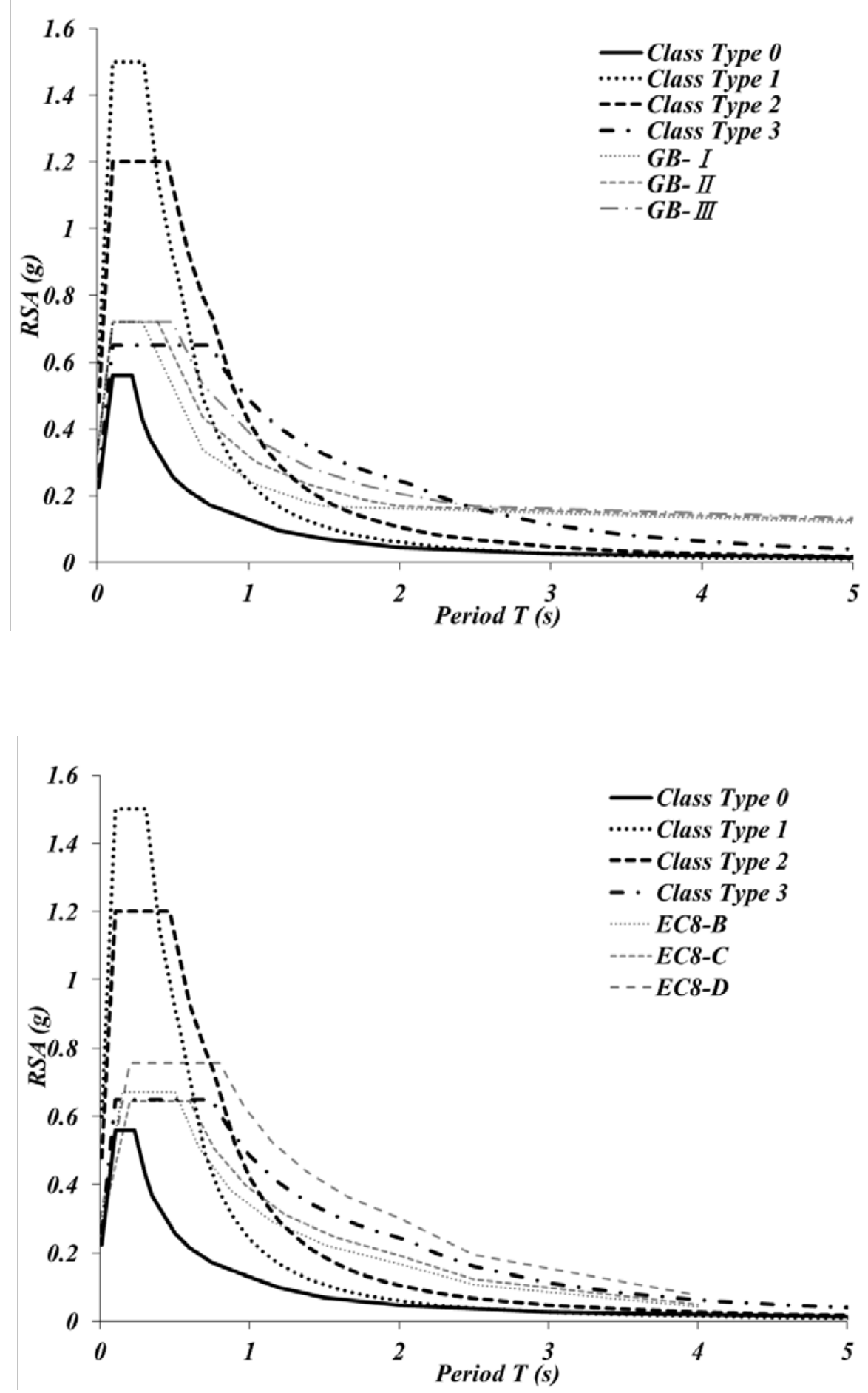

Figure 11 Comparison of the proposed Hong Kong response spectra with those in building codes (RSA with a return period of 2475 years) 